\title{
To assess the correlation between caries prevalence and caries related factors in 6- 12 year old children in various districts of Uttarakhand
}

\author{
Pradeep K. Rastogi ${ }^{1}$, Monika Varshney ${ }^{2, *}$, Avantika Tuli ${ }^{3}$, Preeti Dhawan ${ }^{4}$ \\ ${ }^{1,3}$ Professor, ${ }^{2}$ Post graduate Student, ${ }^{4}$ Professor \& HOD, Dept. of Pedodontics \& Preventive Dentistry, \\ *Corresponding Author: \\ Email: mvarshney1990@gmail.com
}

\begin{abstract}
Introduction: The present study was conducted to assess the prevalence of dental caries in 6-12 years old school going children in various districts of Uttarakhand including those visiting the OPD of the Department of Pedodontics and to correlate the caries status of the study population with the caries related factors.

Materials and Methods: The study was conducted on a sample size of approximately 1200 school going children (both males and females) aged 6-12 years. Oral examination of the children was performed and data was recorded with the help of Questionnaire which contained queries regarding the demographic details, oral hygiene habits, frequency of snacking and visits to the dentist. The findings of the present study were then recorded and analysed statistically.

Results and Conclusion: The results of the present epidemiological study revealed that prevalence of dental caries was more in females, more in age group of 11-12 years children. It was noted that the children who did not brush their teeth or brushed once a day had a higher prevalence of caries. It was also seen that caries prevalence was more in children who consumed sweets and candy twice a day and in children who visited the dentist irregularly or had never visited a dentist.
\end{abstract}

Keywords: Dental caries, Prevalence, Dietary habits, Oral hygiene, $\mathrm{pH}$.

\section{Introduction}

The oral cavity is a distinctive ecosystem harvesting different types of hard and soft tissues which harbours plethora of microorganisms and is specialized to perform a wide variety of functions. A number of oral diseases afflict the oral cavity. Among them, dental caries is the most common chronic disease of mankind. ${ }^{1}$ According to WHO "Dental caries is defined as a localized post eruptive, pathological process of external origin, involving softening of hard tooth tissues, and proceeding into the formation of cavity."

The Surgeon General's report in 2000 labelled Dental caries as a "SILENT EPIDEMIC" that is affecting individuals of all ages, cultures, ethnicities, and socioeconomic backgrounds. ${ }^{2}$ It was determined that dental caries was the most common chronic disease of childhood, with a rate five times greater than that seen for the next most prevalent disease of childhood. ${ }^{3}$

It has been recognized as a pandemic disease and its prevalence among school going children is $60-90 \%{ }^{4}$ In Asia the prevalence in 3 years old ranges from 36$85 \%$ while in India a prevalence rate of $44 \%$ has been reported for caries in 8-48 months old children. ${ }^{5}$ Caries is multifactorial disease involving internal defence factors such as saliva, tooth surface morphology and mineralization, general health, nutritional, hormonal status, and a number of external factors such as diet, microbial flora colonizing the teeth, oral hygiene, and fluoride availability. ${ }^{6}$ During mixed dentition period oral hygiene is poor because of care free age, emotional stresses of the child, frequent intake of refined sugars, soft and sticky foods, shedding of deciduous and eruption of permanent teeth. ${ }^{7}$ Caries is controlled to a large extent by a natural protective mechanism inherent within the saliva ${ }^{8}$ which collaborates to prevent dental caries by mechanical washing, antimicrobial function, remineralisation and regulating oral $\mathrm{pH}$ by its buffering capacity. ${ }^{9}$ Microorganisms in the oral cavity rapidly metabolize dietary sugars to acid, creating a low $\mathrm{pH}$ environment locally. ${ }^{10}$

India has a vast geographic area, divided into states which differ with regards to their socioeconomic, cultural and behavioral traditions. These factors may affect oral health. The high prevalence of dental caries may be attributed to local differences in eating habits, oral cleaning habits, fluoride content of water, tooth paste etc. ${ }^{11}$ Therefore, the overall goal of this doctoral research dissertation is to examine the prevalence of dental caries and its correlation with the caries related factors like salivary $\mathrm{pH}$, dietary habits, brushing techniques in children of 6-12 year of age.

\section{Materials and Methods}

The study was conducted on a sample size of approximately 1200 school going children aged 6-12 years attending various schools of Rishikesh state including those visiting the OPD of Department of Pedodontics and Preventive Dentistry, SDCH, Rishikesh. The demographic details and oral health status of the children was recorded in a self designed questionnaire according to their respective age groups.

The subjects were examined on an upright chair in adequate natural light. Both the examiner and assistant were calibrated before the start of study. An investigator administered performa was used for data collection consisting of two parts. First part was used to record the demographic details of the patient and second part recorded the data related to oral hygiene 
habits, snacking habits and regular or irregular oral health checkups. The caries and oral hygiene status was calculated using DMFT/dmft index and OHI Index.

The subjects were examined using plain mouth mirror and probe. All the data was entered in the proforma and results were calibrated using statistical analysis.

\section{Results}

The study population consisted of 1200 subjects out of which 539(44.9\%) were male and 661(55.1\%) were female. According to age there were 544 subjects in 6-8 years age group in which $249(45.8 \%)$ were male and $295(54.2 \%)$ were female. 399 subjects were present in 9-10 years age group in which $180(45.1 \%)$ were male and $219(54.9 \%)$ were female and 257 subjects were present in 11-12 years age group in which $110(42.8 \%)$ were male and $147(57.2 \%)$ were female respectively. (TABLE 1, GRAPH 1)

Table 1: Distribution of study population according to age and gender

\begin{tabular}{|l|c|c|c|c|}
\hline \multirow{2}{*}{} & \multicolumn{3}{|c|}{ Age groups } & \multirow{1}{*}{} \\
\cline { 2 - 4 } & $\begin{array}{c}\mathbf{6 - 8} \\
\text { years }\end{array}$ & $\begin{array}{c}\mathbf{9 - 1 0} \\
\text { years }\end{array}$ & $\begin{array}{c}\mathbf{1 1 - 1 2} \\
\text { years }\end{array}$ & Total \\
\hline Male & 249 & 180 & 110 & 539 \\
\hline & $45.8 \%$ & $45.1 \%$ & $42.8 \%$ & $44.9 \%$ \\
\hline Female & 295 & 219 & 147 & 661 \\
\hline & $54.2 \%$ & $54.9 \%$ & $57.2 \%$ & $55.1 \%$ \\
\hline Total & 544 & 399 & 257 & 1200 \\
\hline & $100.0 \%$ & $100.0 \%$ & $100.0 \%$ & $100.0 \%$ \\
\hline
\end{tabular}

Graph 1: Distribution of study population according to age and gender

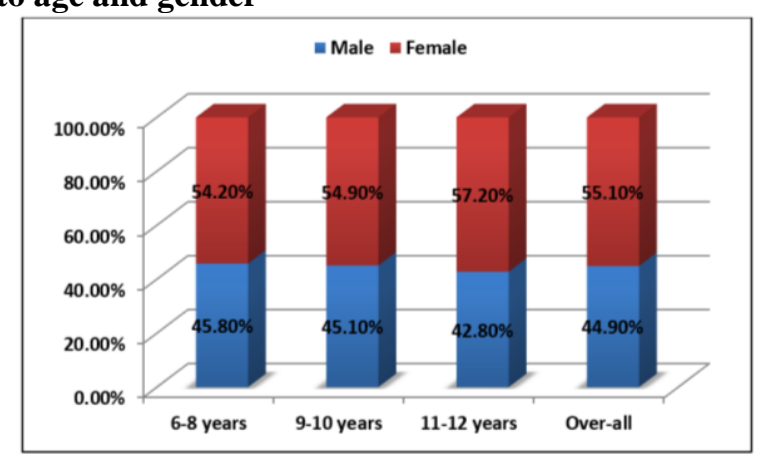

Based on the frequency of brushing among 1200 subjects, 43 children $(100 \%)$ never cleaned their teeth and had DMFT score $\geq 1$.The children who cleaned their teeth once and had a DMFT score $\geq 1$ were found to be $499(89.3 \%)$ followed by $533(89.1 \%)$ children who brushed their teeth twice a day and had a DMFT score $\geq 1$. The prevalence of caries was significantly found to be more in the children who never cleaned their teeth followed by those children who brushed their teeth either once or twice. (TABLE 2, GRAPH 2)
Table 2: Prevalence of caries in permanent dentition based on frequency of brushing

\begin{tabular}{|l|c|c|c|}
\hline $\begin{array}{c}\text { Frequency } \\
\text { of Brushing }\end{array}$ & $\begin{array}{c}\text { DMFT } \\
\text { score = 0 }\end{array}$ & $\begin{array}{c}\text { DMFT } \\
\text { score } \geq \mathbf{1}\end{array}$ & Total \\
\hline None & 0 & 43 & 43 \\
\hline & $0.0 \%$ & $100.0 \%$ & $100.0 \%$ \\
\hline Once & 60 & 499 & 559 \\
\hline & $10.7 \%$ & $89.3 \%$ & $100.0 \%$ \\
\hline Twice & 65 & 533 & 598 \\
\hline & $10.9 \%$ & $89.1 \%$ & $100.0 \%$ \\
\hline Total & 125 & 1,075 & 1,200 \\
\hline & $10.4 \%$ & $89.6 \%$ & $100.0 \%$ \\
\hline
\end{tabular}

Chi-square value $=5.192, \mathrm{p}$-value $=0.045^{*}$

Chi-square test

* Significant difference

\section{Graph 2: Prevalence of caries in permanent dentition based on frequency of brushing}

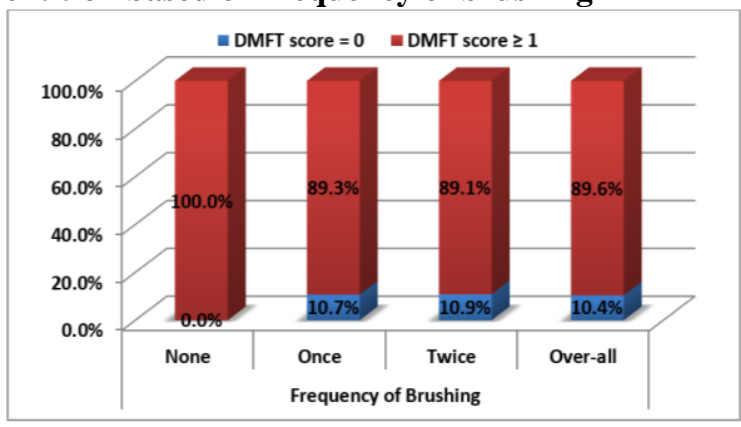

The distribution of study population was 1200 (100\%) out of which children having DMFT score $\geq 1$ was $281(85.4 \%)$ who never taken sweets followed by once and twice having DMFT score $\geq 1$ were $539(89.5 \%)$ and 255(94.8\%) respectively. The prevalence of caries was significantly more 255 (94.8\%) among children who were consuming sweets and candy twice daily as compared to children who were not consuming sweets and candy in their diet. (TABLE 3, GRAPH 3)

Table 3: Distribution of dmft score based on consumiption of sweets \& candy

\begin{tabular}{|l|c|c|c|}
\hline Sweets/ candy & $\begin{array}{c}\text { DMFT } \\
\text { score }=0\end{array}$ & $\begin{array}{c}\text { DMFT } \\
\text { score } \geq \mathbf{1}\end{array}$ & Total \\
\hline None & 48 & 281 & 329 \\
\hline & $14.6 \%$ & $85.4 \%$ & $100.0 \%$ \\
\hline Once & 63 & 539 & 602 \\
\hline & $10.5 \%$ & $89.5 \%$ & $100.0 \%$ \\
\hline Twice & 14 & 255 & 269 \\
\hline & $5.2 \%$ & $94.8 \%$ & $100.0 \%$ \\
\hline Total & 125 & 1,075 & 1,200 \\
\hline & $10.4 \%$ & $89.6 \%$ & $100.0 \%$ \\
\hline
\end{tabular}

Chi-square value $=13.972$, $\mathrm{p}$-value $=0.001^{*}$

Chi-square test

* Significant difference 


\section{Graph 3: Distribution of DMFT score based on consumption of sweets \& candy}

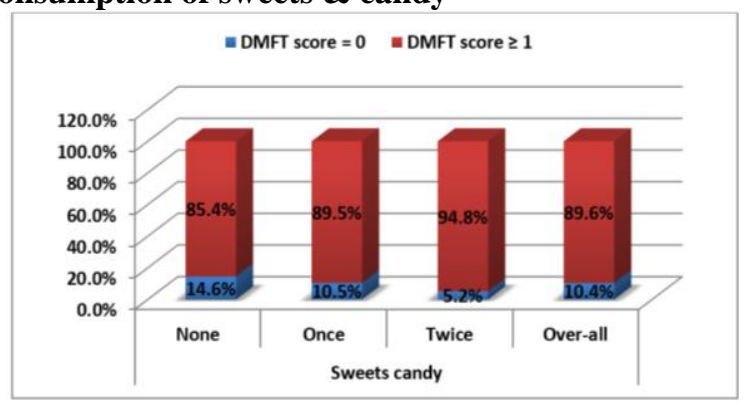

Out of the 1200 subjects studied, the children who visited the dentist once in 6 months and had a DMFT score $\geq 1$ were $338(88.5 \%)$ and the children who visited the dentist when problem arose were $737(91.8 \%)$. The prevalence of DMFT score was significantly more among children who visited the dentist only when problem arose in comparison to those who visited once in 6 months. (TABLE 4, GRAPH 4)

Table 4: Prevalence of caries (DMFT) on the basis of frequency of visiting the dentist

\begin{tabular}{|l|c|c|c|}
\hline $\begin{array}{c}\text { Frequency of } \\
\text { visiting the } \\
\text { dentist }\end{array}$ & $\begin{array}{c}\text { DMFT } \\
\text { score = 0 }\end{array}$ & $\begin{array}{c}\text { DMFT } \\
\text { score } \geq \mathbf{1}\end{array}$ & Total \\
\hline $\begin{array}{l}\text { Once in 6 } \\
\text { months }\end{array}$ & 59 & 338 & 397 \\
\hline & $14.9 \%$ & $85.1 \%$ & $100.0 \%$ \\
\hline $\begin{array}{l}\text { When problem } \\
\text { arises }\end{array}$ & 66 & 737 & 803 \\
\hline & $8.2 \%$ & $91.8 \%$ & $100.0 \%$ \\
\hline Total & 125 & 1,075 & 1,200 \\
\hline & $10.4 \%$ & $89.6 \%$ & $100.0 \%$ \\
\hline
\end{tabular}

Chi-square value $=12.560, \mathrm{p}$-value $=0.001^{*}$

Chi-square test

* Significant difference

Graph 4: Prevalence of caries (DMFT) on the basis of frequency of visiting the dentist

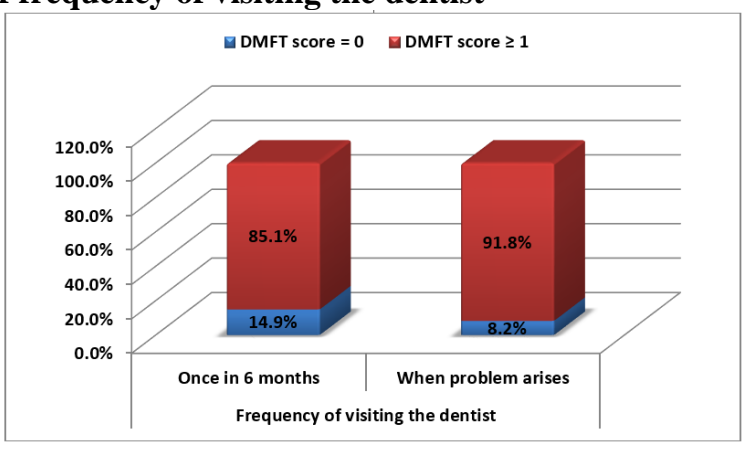

\section{Discussion}

Dental caries is a multi-factorial disease that starts with microbiological shifts within the complex bio film (dental plaque). Caries is affected by the consumption of dietary sugars, salivary flow; exposure to fluoride and preventive behaviours. ${ }^{12}$ The impact of dental caries includes destruction of the dental structure and oral pain which may affect speech, eating, sleeping, and swallowing of food. The altered appearance it causes can also lead to low self-esteem and undermine social acceptance.

In the present study the prevalence of dental caries was significantly higher (90.4\%) in females when compared to males $(88.6 \%)$. Similar findings were seen by Rai $\mathrm{B},{ }^{13}$ Mishra $\mathrm{FM}^{14}$ and Mosha $\mathrm{HJ}^{15}$ who in their studies also reported increased caries prevalence for females. The results of the present study were not in agreement with the study done by Sudha P, Bhasin S and Anegundi $\mathrm{RT}^{16}$ as they reported increased prevalence of dental caries for males. Also the study conducted by Gathecha $G$ et $\mathrm{al}^{17}$ revealed that the difference in prevalence of dental caries between boys and girls was not significant.

Significant difference was noted in dental caries status between males and females which was similar to studies conducted by Bhagat TK and Shrestha $\mathrm{A}^{18}$. The reason behind the similarities between this study and others might be because of the similar characteristics of sample size, food habits and environment while dissimilarities might be due number of sample size or due to the fact that the children are deprived of oral health education programs or access to dental health care services.

The overall prevalence of dental caries among the school going children aged between 6-12 years was found to be $63.9 \%$ which is in concordance with the study by Karunakaran $\mathrm{R}$ et $\mathrm{al}^{19}$ which was conducted among children aged between 5-10 years in which the prevalence of dental caries was $65.9 \%$. Dhar V and Bhatnagar $\mathrm{M}^{20}$ in their study among children aged between 6-10 years reported the prevalence of dental caries to be $63.2 \%$ and Parasuraman $\mathrm{G}$ et $\mathrm{al}^{21}$ in their study in school children 5-18 years of age found the prevalence of dental caries to be $30.9 \%$ which is far below the prevalence in the present study and this discrepancy can be attributed to different age groups. In this study, prevalence of dental caries among the children of age group of 11-12 years were $91.4 \%$ that was higher than the prevalence of dental caries among children of 6-8 years of age group. This shows that as the age advances the prevalence of dental caries escalates. Higher DMFT was found in the age group of 10-12 years than age group of 6-8 years and this could be explained on the basis of increased exposure of the teeth to poor oral hygiene conditions and other caries related factors. Mahesh Kumar $\mathrm{P}^{22}$ in their study found that among the children aged 5 year old boys, DMFT noted was $3.53 \pm 3.07$ and in girls it was $3.49 \pm 2.83$ ) while among the children aged 12 years the DMFT for boys was $3.80 \pm 3.43$, and for girls it was $4.11 \pm 2.98$ and hence the caries prevalence of 12 years age group was higher as compared to the 5 years age group in both sexes. 
In this study oral hygiene practices like frequency of brushing the teeth among the study participants was noted and it was found that $235(65.8 \%)$ participants brushed their teeth once a day while $122(34.2 \%)$ participants brushed their teeth about twice or more than twice a day. Prabhakar J, John J and Shrisakthi $\mathrm{D}^{23}$ from their study reported that a total of $2708(60.3 \%)$ study subjects brushed their teeth once daily and 1785 (39.7\%) subjects who brushed their teeth twice daily. It was found that those who brushed their teeth about twice or more than twice a day $(20.2 \%)$ had lower prevalence of dental caries than those who brushed their teeth once a day (79.8\%) and this difference was highly significant $(\mathrm{p}=0.000)$ and was in concordance with Shailee F, Girish MS, Kapil RS and Nidhi P. ${ }^{24}$

Reports from various countries in the world and from India suggest that consumption of sugar or sugar confectionery like sweets or candy are significant risk factors for caries. Magnusson K, Strunberg V and Twetnan $S^{25}$ observed that consumption of food containing high cariogenicity score (food cariogenicity combined with the frequency of consumption) was found to be a significant risk indicator of dental caries. Khan AA, Jain SK and Shrivastav $\mathrm{A}^{26}$ in their study reported that $34.2 \%$ of the students who consumed sweets like candy and chocolates while $14.3 \%$ of them who did not consume sweets like candy and chocolates developed dental caries and this difference was statistically significant which was in accordance with the present study in which the prevalence of caries was more in children who consumed sweets and candy twice a day in comparison to children who consumed them once in a day.

According to a study conducted by Al-Samadani $\mathrm{KH}^{27}$ visiting the dentist benefits a child's dental health, and it is recommended to visit the dentist twice a year to protect oral health. The result from present study shows prevalence of decayed teeth was high $(85.5 \%)$ among subjects who never visited a dentist subjects in comparison to those who visited the dentist only when a problem arose was $(63.8 \%)$ or $(48.4 \%)$ among subjects who visited the dentist once in every 6 months. Significantly higher prevalence of caries was seen in children who had never visited a dentist. It was also noted that a great number of female students (32\%) never visited the dentist. This might be due to not getting proper access because they are dependent on the parents (male members) who take them to the dentist or they are ashamed to describe the disease to parents because of social culture.

\section{Conclusion}

The present study has revealed a direct relationship between oral hygiene habits, snacking habits and caries prevalence in children. Therefore, dental professionals need to focus more on primary prevention of dental caries through public awareness on oral health promotion and education.

\section{References}

1. Grewal N, Kaur M. Status of oral health awareness in India children as compared to Western children. J Indian Soc Pedod Prev Dent 2007; 25(1):15-9.

2. World Health Organizations. The world oral health report 2003.

3. Peter S et al. Essentials of Preventive and Community Dentistry. First edition.1999;134-8.

4. Das UM, Beena JP, Azher U. Oral health status of 6- and 12-year-old school going children in Bangalore city: An epidemiological study. J Indian Soc Pedod Prev Dent 2009;27:6-8.

5. Saravanan S, Madivanan I, Subashini B, Felix JW Prevalence pattern of dental caries in the primary dentition among school children. Indian Journal of Dental Research 2005;67-9.

6. Gathecha G, Makokha A, Wanzala P, Omolo J, Smith P. Dental caries and oral health practices among 12 year old children in Nairobi West and Mathira West Districts, Kenya Pan African Medical Journal. 2012;12:42.

7. Joshi N, Sujan SG, Joshi K, Parekh H, Dave B. Prevalence, severity and Related factors of dental caries in school going children of Vadodara city- An Epidemiological study. J Int Oral Health 2013; 5(4):40-8.

8. Kwon HK, Suh I, Kim YO, Kim HJ, Nam CM, Jun KM. Relationship between nutritional intake and dental caries experience of junior high students. Yonsei Med J 1997; 38(2):101-10.

9. Kolker JL, Yuan Y, Burt BA, Sandretto AM, Sohn W. Dental caries and dietary patterns in low-income African American children. Pediatr Dent 2007;29(6):457-64.

10. Berkowitz RJ. Mutans streptococci acquisition and transmission. Peadiatr Dent. 2006; 28:106-9.

11. Friedman LA, Mackler IG, Hoggard GJ, French CI; A comparison of perceived and actual dental needs of a selected group ofchildren in Texas. Community Dent Oral Epidemiol.1976;4:89-93.

12. Sundby A, Petersen PE; Oral health status in relation to ethnicity of children in the Municipality of Copenhagen, Denmark. Int J Paediatr Dent., 2003;13:150-7.

13. Rai B, Shakya A, Shrestha M, Shrestha A. Dental caries prevalence, oral health knowledge and practice among indigenous Chepang school children of Nepal. BMC Oral Health 2013;13-20.

14. Misra FM, Shee BK. Prevalence of dental caries in school going children in an urban area of South Orissa. J Indian Dent Assoc 1979;51:267-70.

15. Mosha HJ, Senkoro AR, Masalu JR. Oral health status and treatment needs among Tanzanian of different age groups, Tanzania. Tanzan Dent J 2005;12:18-27.

16. Bhagat TK, Shrestha A Prevalence of Dental Caries among public school children in Eastern Nepal. Journal of Chitwan Medical College 2014;4(7):30-2.

17. Rajesh SS, Venkatesh P. Prevalence of dental caries among school-going children in South India. Int J Med Sci Public Health 2016;5:700-04.

18. Karki S, Wangdu K, Kunwar N, Namgyal K. Prevalence of Dental Caries Among 6-12 Years old Tibetan Children Residing in Nepal. Int J Dent Med Res 2015;1(6):51-3.

19. Nadanu TA, Aryeetey R, Sackeyfio J, Otoo G, Lartey A. Oral Hygiene Practices and Caries Prevalence among 9. 15 Years Old Ghanaian School Children. J Nutr Health Sci;20152(1):104

20. Mudola JM, Nyangena E, Muchee T. Factors Influencing Compliance with Oral Hygiene Practices Among Upper Primary School Children at Eldoret Town in Uasin Gishu County, Kenya. J Nurs Care 2015;1: 9. 
21. Aasim Farooq Shah, Manu Batra, Soumik Kabasi, Subha Soumya Dany, Prashant Rajput. Dental caries experience among 6-12 year old school children of Budgam district, Jammu. and Kashmir state, India.Asian Pac. J. Health Sci., 2015;2(1):55-59.

22. Abduljalil HS, Abuaffan AH. Knowledge and Practice of Mothers in Relation to Dental Health of Pre-School Children. Adv Genet Eng. 2016;5(3):153.

23. Pinto GS, Hartwig AD, Elias R, Azevedo MS, Goettems ML, Correa MB, Demarco FF. Maternal care influence on children's caries prevalence in southern Brazil. Braz. Oral Res. 2016;30(1):70.
24. Tomar SP, Kasar PK, Tiwari R. Study of oral hygienic practices and oral health status among school children in Jabalpur, Madhya Pradesh: a cross-sectional study. Int J Community Med Public Health 2016; 3:403-7.

25. Selwitz RH, Ismail AI, Pitts NB: Dental caries. Lancet 2007;369:51-9.

26. Weir E. Dental caries: a nation divided. Canadian Medical Association Journal 2002;167(9):1035.

27. Petersen P.E. Oral Health. International encyclopedia of public health. Academic press.2008; 4:677-85. 